Известия НАН Армении, Физика, т.57, №1, с.109-115 (2022)

УДК 541.14

DOI:10.54503/0002-3035-2022-57.1-109

\title{
ЭЛЕКТРОДНЫЙ МАТЕРИАЛ ДЛЯ СУПЕРКОНДЕНСАТОРОВ НА ОСНОВЕ ПРОДУКТОВ ТВЕРДОФАЗНОГО ПИРОЛИЗА МЕТАЛЛ-ФТАЛОЦИАНИНОВ
}

\author{
А.Т. ГЮЛАСАРЯН ${ }^{*}$, Г.Г. АЗИЗБЕКЯН ${ }^{1}$, Н.С. СИСАКЯН ${ }^{1}$, \\ Г.Н. ЧИАЛИНГАРЯН ${ }^{1}$, Д.В. ГРАПОВ ${ }^{2}$, Ю.М. КУКУТЬ ${ }^{2}$, \\ Э.Г. ШАРОЯН ${ }^{1}$, А.С. МАНУКЯН ${ }^{1}$ \\ ${ }^{1}$ Институт физических исследований НАН Армении, Аштарак, Армения \\ ${ }^{2}$ Белорусский государственный университет информатики и радиоэлектроники, \\ Минск, Беларусь \\ *e-mail: gharut1989@gmail.com \\ (Поступила в редакцию 27 октября 2021 г.)
}

\begin{abstract}
Путем твердофазного пиролиза фталоцианина никеля $\left(\mathrm{NiC}_{32} \mathrm{~N}_{8} \mathrm{H}_{16}\right)$ и фталоцианина кобальта $\left(\mathrm{CoC}_{32} \mathrm{~N}_{8} \mathrm{H}_{16}\right)$ получены нанокомпозиты $\mathrm{Ni} @ \mathrm{C}$ в графитоподобной углеродной матрице и наночастицы кобальта в углеродных нанотрубках. Концентрации металла в углеродной матрице в обеих случаях и в $\mathrm{Ni} / \mathrm{C}$ и в $\mathrm{Co} / \mathrm{C}$ одинаковы - 12 вес\%. Структура и морфология полученных образцов исследованы методами сканирующей и просвечивающей электронной микроскопии высокого разрешения и рентгеновской дифракции. Исследованы емкостные и резистивные характеристики полученных соединений $\mathrm{Ni} / \mathrm{C}$ и $\mathrm{Co} / \mathrm{C}$ в качестве электродного материала для суперконденсаторов (СК). Удельные ёмкости измеренные методом циклической вольтамперометрии равны 12 Ф/г и 8 Ф/г для образцов $\mathrm{Ni} / \mathrm{C}$ и $\mathrm{Co} / \mathrm{C}$, соответственно. Синтезированные соединения могут стать перспективным электродным материалом для суперконденсаторов с электролитным раствором $\mathrm{H}_{2} \mathrm{SO}_{4}$.
\end{abstract}

\section{1. Введение}

В настоящее время суперконденсаторы (СК) играют исключительно важную роль в сфере передовых технологий из-за их способности накопления большого количества заряда и более длительного срока службы, чем стандартные батареи [1-3]. Основными преимуществами СК являются простой способ зарядки, быстрая зарядка/разрядка, малое внутреннее сопротивление, способность выдерживать более 500000 циклов зарядки/разрядки, устойчивость температурного рабочего диапазона, отсутствие химических реакций, а также экологическая безопасность [4-7]. Электродные материалы для СК можно разделить на три типа в зависимости от их использования - для электростатических двухслойных конденсаторов (EDLC), псевдоконденсаторов и гибридных CK [8-10]. В настоящее 
время доступно много материалов для СК, значительная часть которых основана на различных модификациях углерода. $[11,12]$. Другие материалы включают оксиды металлов, никеля, кобальта, марганеца и рутения [13-16]. Наряду с оксидами металлов проводящие полимеры также используются в суперконденсаторах. В последнее время суперконденсаторы все чаще основываются на углеродных нанотрубках или других наноматериалов, использование которых, помимо других преимуществ, позволяет значительно увеличить площадь поверхности электродов [17,18]. Также, для улучшения емкостных характеристик электродов СК используются различные нанокомпозиты, например - углеродные нанотрубки с проводящими полимерами или оксидами металлов $[19,20]$.

В данной работе для изготовления электродов для суперконденсаторов исследованы продукты твердофазного пиролиза фталоцианина никеля $\left(\mathrm{NiC}_{32} \mathrm{~N}_{8} \mathrm{H}_{16}\right)$ и фталоцианина кобальта $\left(\mathrm{CoC}_{32} \mathrm{~N}_{8} \mathrm{H}_{16}\right)$. Твердофазный пиролиз металл-фталоцианинов обеспечивает одностадийное образование различных металл-углеродных структур с заданными характеристиками (см., например, [21-25]). Преимуществами данного метода являются простота, экономичность и большая выходная масса конечного продукта. В настоящей работе изучены структура, морфология, а также емкостные и резистивные характеристики полученных нами соединений.

\section{2. Материалы и методы исследований}

Образцы для исследования были получены методом твердофазного пиролиза металл-фталоцианинов, описанным в наших работах [21-25]. Реакцию пиролиза металл-фталоцианинов можно представить следующей схемой:

$$
\mathrm{M}\left(\mathrm{C}_{32} \mathrm{~N}_{8} \mathrm{H}_{16}\right) \underset{\mathrm{T}_{\mathrm{pyr}}, \mathrm{t}_{\mathrm{pyr}}, \mathrm{p}_{\mathrm{pyr}}}{-8 \mathrm{H}_{2},-4 \mathrm{~N}_{2}} \mathrm{M}+32 \mathrm{C},
$$

где $T_{\mathrm{pyr}}$ - температура пиролиза, $t_{\mathrm{pyr}}-$ время пиролиза, $p_{\mathrm{pyr}}$ - самогенерированное давление в реакционной ампуле.

Пиролиз проводился в замкнутой кварцевой ампуле при начальном давлении $\sim 10^{-6}$ bar. Параметры пиролиза: для фталоцианина никеля $T_{\mathrm{pyr}}=700{ }^{\circ} \mathrm{C}$, для фталоцианина кобальта $T_{\mathrm{pyr}}=1000^{\circ} \mathrm{C}, t_{\mathrm{pyr}}=30$ мин. При данных параметрах пиролиза, в соответствии с формулой 1 , концентрация метала в синтезированных образцах составляет 3 ат\%, что соответствует 12 вес\%.

Морфология, элементный состав и размеры полученных наночастиц были исследованы с помощью сканирующего электронного микроскопа (СЭМ) Vega TS 5130 (Tescan) с системой энергодисперсионного рентгеновского микроанализа INCA Energy 300 и просвечивающего электронного (трансмиссионного) микроскопа высокого разрешения (ПЭМ) FEI Tecnai. Структура полученных образцов определялась с помощью рентгеновского дифрактометра X'PERT PRO (PANalytical, Nederland's) с длиной волны возбуждающего излучения $\left(\mathrm{CuK}_{\alpha}\right) \lambda=1.5418 \AA$. Электрические характеристики суперконденсаторной структуры исследовали с помощью потенциостата AUTOLAB PGSTAT302n. 


\section{3. Результаты экспериментов и их обсуждение}

На рис.1 представлены СЭМ и ПЭМ изображения полученных нами соединения $\mathrm{Ni} / \mathrm{C}$ и $\mathrm{Co} / \mathrm{C}$. Во время пиролиза никель-фталоцианина образуется углеродная матрица в форме «плиток» (рис.1а).

Размер плиток варьирует в интервале 5-15 $\mu$ м. В плитках внедрены наночастицы никеля, которые в свою очередь покрыты графитоподобной углеродной оболочкой (рис. $1 \mathrm{~b}$ ). Средний размер наночастиц никеля составляет $\sim 60$ нм. В отличие от никель-фталоцианина, в случае пиролиза кобальт фталоцианина основная часть углерода преобразовывается в многостенные углеродные нанотрубки (рис.1c). Толщина стенок углеродных нанотрубок составляет 10нм, диаметр 5060 нм (рис.1d). Наиболее крупные наночастицы (с диаметром 50нм) вырастают в углеродные нанотрубки, а наночастицы диаметром $\sim 5$ нм, локализованы между стенками нанотрубок.

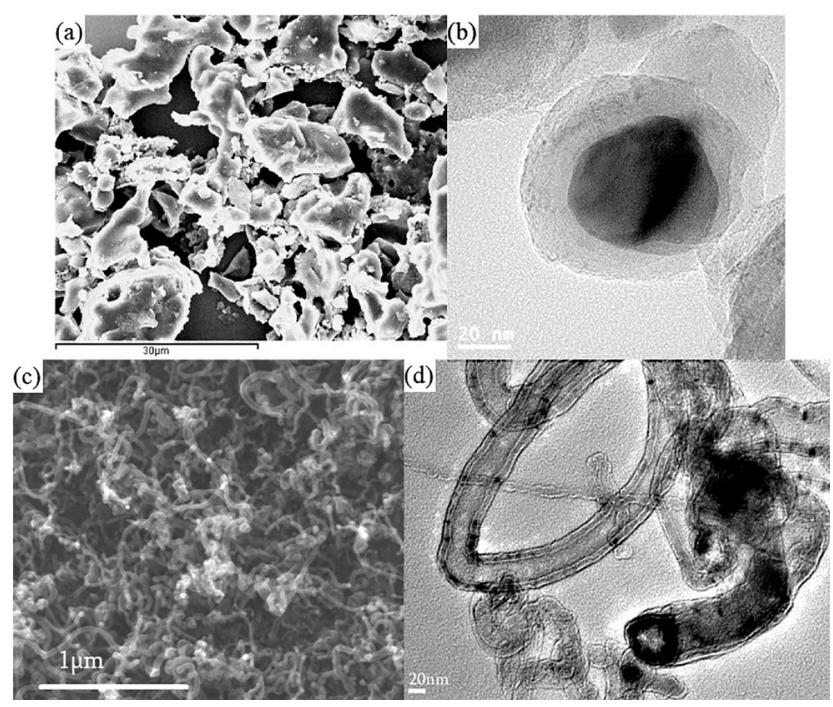

Рис.1. СЭМ изображения и ПЭМ изображения высокого разрешения образцов $\mathrm{Ni} / \mathrm{C}-(\mathrm{a})$ и (b); $\mathrm{Co} / \mathrm{C}-$ (c) и (d).

На рис.2 представлены рентгеновские дифракционные спектры образцов $\mathrm{Ni} / \mathrm{C}$ и $\mathrm{Co} / \mathrm{C}$, записанные при комнатной температуре, где видны пики металлов и углеродной матрицы. Широкий пик около $26^{\circ}$ рис.2а соответствует графитоподобным углеродным структурам ( $\mathrm{d}_{002} \approx 0.350$ нм), а четыре узких пика с $2 \theta=$ $44.32^{\circ}(111), 51.64^{\circ}(200), 76.02^{\circ}(220)$ и $92.44^{\circ}$ (311) соответствуют нанокристаллам никеля с ГЦК-структурой [12]. Три узких пика с $2 \theta=44.23^{\circ}(111), 51.52^{\circ}$ (200) и $76.02^{\circ}(220)$ на рис.2b, соответствуют нанокристаллитам кобальта c ГЦК - структурой [13].

Для измерения емкости и внутреннего сопротивления СК на основе соединения $\mathrm{Ni} / \mathrm{C}$ и $\mathrm{Co} / \mathrm{C}$ в специальной измерительной ячейке были изготовлены два одинаковых по массе электрода с геометрическими размерами $1 \times 1 \mathrm{~cm}^{2}$ и с 

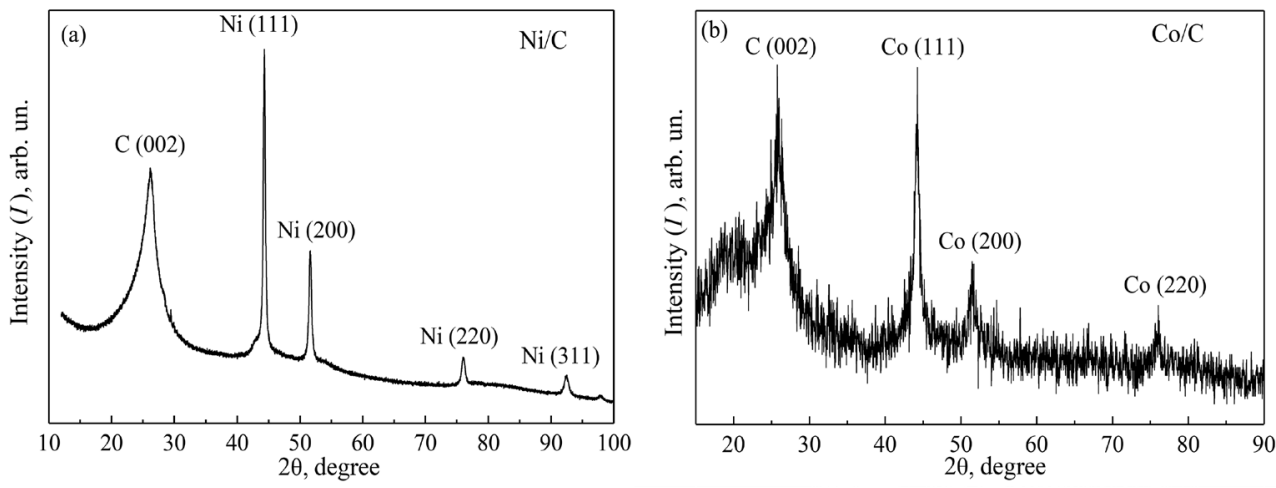

Рис.2. Спектры рентгеновской дифракции образцов (a) Ni/C и (b) Co/C.

толщиной слоя 100 мкм. Электроды смачивались электролитом - одномолярным водным раствором серной кислоты. Между электродами размещали пористый мембранный сепаратор на основе полисульфона.

Для исследования емкостных характеристик суперконденсаторной структуры использовался метод циклической вольтамперометрии. Из графика циклической вольтамперометрии определялась удельная емкость электродного материала в единицах $\Phi / г$ :

$$
C=\frac{S}{2 k m \Delta U},
$$

где $S$ - площадь гистерезиса вольтамперограммы, $A \times B ; m-$ масса электрода, г; $k$ - скорость развертки напряжения, $\mathrm{B} / \mathrm{c} ; \Delta U$ - диапазон изменения напряжений, $\mathrm{B}$.

Типичные кривые циклической вольтамперограммы СК в диапазоне напряжения от -1 до 1В при скорости сканирования 100 мВ/с показаны на рис.3. Как видим из рис. 3 вольтамперограмма на основе $\mathrm{Co} / \mathrm{C}$ в отличие от $\mathrm{Ni} / \mathrm{C}$ имеет квазипрямоугольную форму, что указывает на хорошее ёмкостное поведение, основанным на двухслойной ионной адсорбции и обменным токам. Кроме того, кривая с хорошей прямоугольной формой указывает на то, что электрод обладает
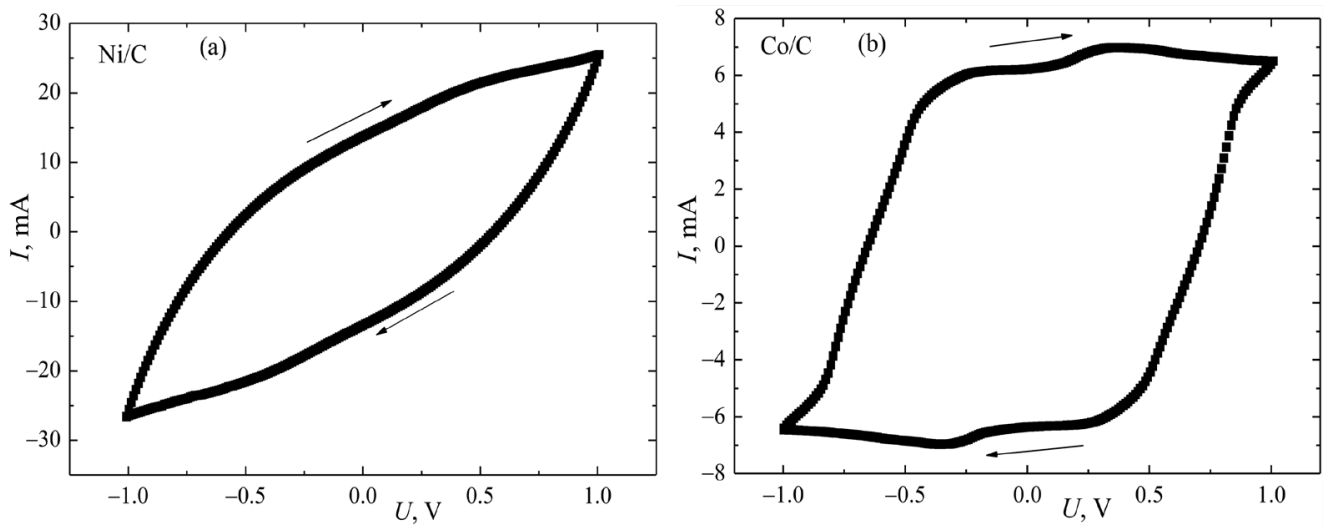

Рис.3. Вольтамперограммы при скорости сканирования 100 мВ/с: СК на основе (a) $\mathrm{Ni} / \mathrm{C}$ и (b) $\mathrm{Co} / \mathrm{C}$. 
характеристиками быстрого заряда и разряда [14]. Удельная ёмкость электродних материалов на основе $\mathrm{Ni} / \mathrm{C}$ и $\mathrm{Co} / \mathrm{C}$, составляет 12 Ф/г и 8 Ф/Г соответственно.

Суперконденсаторная структура дополнительно исследовалась методом гальваностатического заряда-разряда. По данным термодинамической стабильности воды максимальное теоретическое напряжение электрохимических конденсаторов в водном электролите ниже 2 В. На практике для систем, работающих в средах $\mathrm{KOH}$ или $\mathrm{H}_{2} \mathrm{SO}_{4}$, напряжение ограничено до 1В. Кривые гальваностатического разряда в водном растворе одномолярного электролита $\mathrm{H}_{2} \mathrm{SO}_{4}$, при зна-

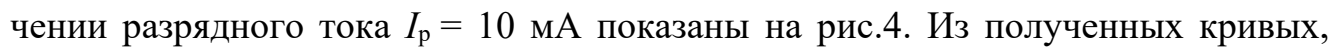
определены значения $\Delta U$ и соответственно внутреннее сопротивление электродов $R$ по формуле $\Delta U=2 I_{\mathrm{p}} R$.
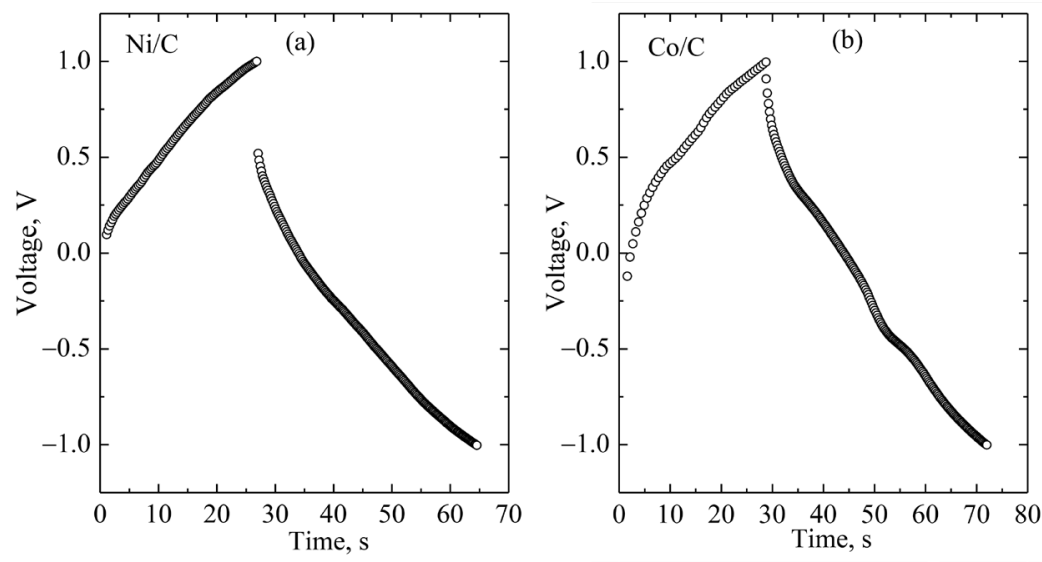

Рис.4. Кривые заряда-разряда СК на основе (a) Ni/C и (b) Co/C при постоянном токе разряда 10 мА.

Измеренное значение внутреннего сопротивления СК на основе $\mathrm{Ni} / \mathrm{C}$ и $\mathrm{Co} / \mathrm{C}$ соединений, равны 28 и 4 Ом соответственно. В целях повышения удельной эффективности хранения заряда и энергетической производительности требуется дополнительная оптимизация параметров системы. Низкое внутреннее сопротивление кобальтсодержащих углеродных нанотрубок связано с большой площадью активной поверхности, что приводит к увеличению количества транспортных пор для переноса заряда.

\section{4. Заключение}

Измеренные емкостные и резистивные характеристики продуктов твердофазного пиролиза фталоцианинов никеля и кобальта показывают, что эти соединения могут стать перспективными электродными материалами для суперконденсаторов с электролитным раствором $\mathrm{H}_{2} \mathrm{SO}_{4}$. Число предлагаемых нами электродных материалов для СК отнюдь не ограничено образцами $\mathrm{Ni} / \mathrm{C}$ и $\mathrm{Co} / \mathrm{C}$. Много различных образцов можно получить, меняя природу и концентрацию металла в соединениях M/C (M = Ni, $\mathrm{Co}, \mathrm{Fe}, \mathrm{Cu}, \mathrm{Zn}, \mathrm{Mg}$ и др.). Однако очевидно, что в соединениях M/C наиболее важным и главным фактором является 
наноразмерная углеродная матрица. Выбор соответствующих параметров твердофазного пиролиза позволяет синтезировать разные наноразмерные аллотропные модификации углерода, такие как углеродные нанотрубки, нанографеновые и нанографитовые слоистые структуры, стеклоуглерод, углеродные микро- и наносферы. Образцы M/C - высокодисперсный пористый материал, в котором различные наноразмерные матрицы углерода имеют большую внутреннюю активную поверхность, которая необходима для получения больших удельных емкостей.

Исследование выполнено при финансовой поддержке КН МОНКС РА и ГКНТ РБ в рамках совместного научного проекта № ArmBel-Ap18_1с_2 и Т18АРМГ-001 соответственно.

\section{ЛИТЕРАТУРА}

1. C. Liu, F. Li, L.-P. Ma, H.M. Cheng. Adv. Mater., 22, 28 (2010).

2. Y. Wang, Y. Xia. Adv. Mater., 25, 5336 (2013).

3. A. Chu, P. Braatz. Journal of Power Sources, 112, 236 (2002).

4. J.R. Miller, I. Simon. Science, 321, 651 (2008).

5. R. Kötz, M.Carlen. Electrochim. Acta, 45, 2483 (2000).

6. M. Stoller, S. Park, Y. Zhu, J. An, R. Ruoff. Nano Lett., 8, 3498 (2008).

7. A.S. Aricò, P. Bruce, et al. Nature Materials, 4, 366 (2005).

8. M. Endo, T. Takeda, Y. Kim, K. Koshiba, K. Ishii. Carbon Sci., 1, 117 (2001).

9. G. Wang, L. Zhang, J. Zhang. Chem. Soc. Rev., 41, 797 (2012).

10. P. Forouzandeh, V. Kumaravel, S.C. Pillai, Catalysts, 10, 969 (2020).

11. E. Frackowiak, F. Beguin. Carbon, 39, 937 (2001).

12. L.L. Zhang, X.S. Zhao. Chem. Soc. Rev., 38, 2520 (2009).

13. J.P. Zheng, P.J. Cygan, et al. J. Electrochem. Soc., 142, 2699 (1995).

14. Y. Zheng, H. Ding, M. Zhang, Materials Research Bulletin, 44, 403 (2009).

15. G.S. Jang, S. Ameen, M.S. Akhtar, H.S. Shin. Ceram. Int., 44, 588 (2018).

16. M. Sawangphruk, P. Srimuk, P. Chiochan, A. Krittayavathananon, S. Luanwuthi, J. Limtrakul. Carbon, 60, 109 (2013).

17. K. Wei, I.S. Kim, (2014) Application of Nanofibers in Supercapacitors. In: Ding B., Yu J. (eds) Electrospun Nanofibers for Energy and Environmental Applications. Nanostructure Science and Technology. Springer, Berlin, Heidelberg.

18. Q.L. Chen, K.H. Xue, W. Shen, F.F. Tao, S.Y. Yin, W. Xu. Electrochimica Acta, 49, 4157 (2004).

19. K. Jurewicz, S. Delpeux, et al. Chemical Physics Letters, 347, 36 (2001).

20. A. L. M. Reddy, S Ramaprabhu, Physical Chemistry C, 111, 7727 (2007).

21. А.С. Манукян, А.А. Мирзаханян, Г.Р. Бадалян, Г.О. Ширинян, Э.Г.Шароян. Изв. НАН Армении, Физика, 45, 202 (2010).

22. А.С. Манукян, А.А. Мирзаханян, Т.К. Хачатрян, Г.Р. Бадалян, К.Г. Абдулвахидов, Л.А. Бугаев, Э.Г. Шароян. Изв. НАН Армении, Физика, 47, 442 (2012).

23. A.S. Manukyan, A.A. Mirzakhanyan, G.R. Badalyan, G.H. Shirinyan, A.G. Fedorenko, N.V. Lianguzov,Yu.I. Yuzyuk, L.A. Bugaev, E.G. Sharoyan. 
J. Nanopart. Res., 14, 982 (2012).

24. A.S. Manukyan, A.A. Mirzakhanyan, T.K. Khachatyran, R.D. Khachaturyan, G.R. Badalyan, E.G. Sharoyan. Armenian J. Physics, 6, 61 (2013).

25. A. Manukyan, A. Mirzakhanyan, L. Sajti, R. Khachaturyan, E. Kaniukov, L. Lobanovsky, E. Sharoyan. NANO, 10, 1550089 (2015).

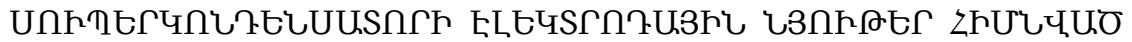

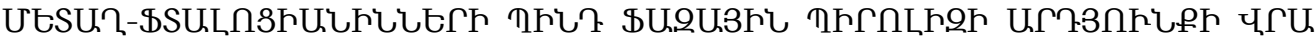

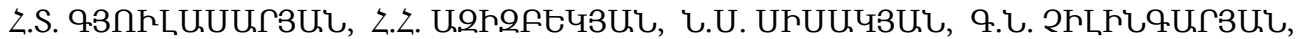

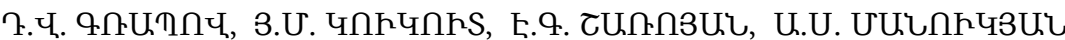

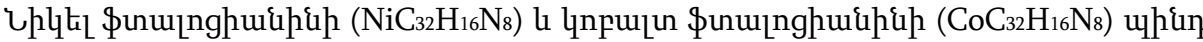

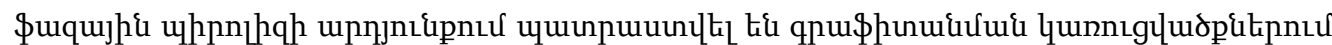

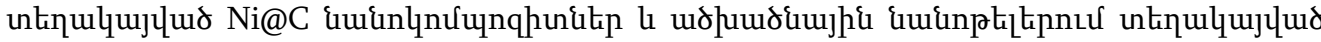

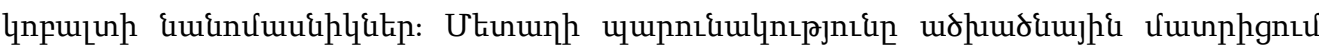

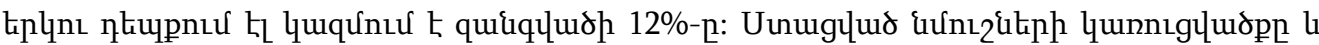

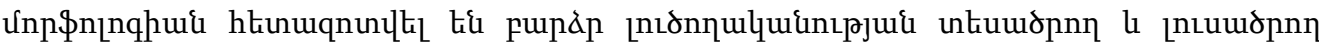

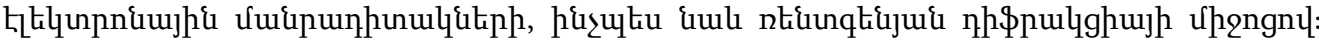

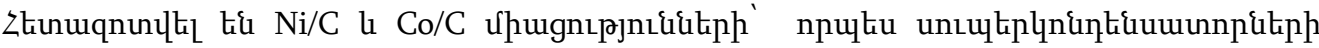

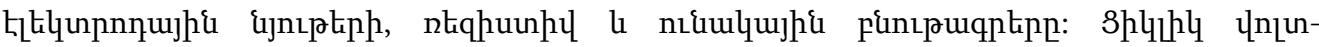

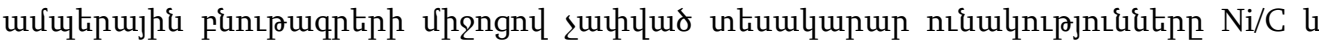

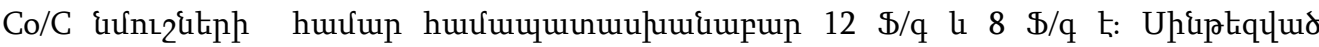

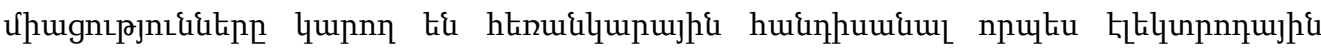

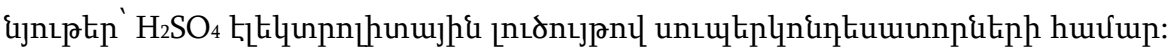

\section{ELECTRODE MATERIAL FOR SUPERCAPACITORS BASED ON PRODUCTS OF SOLID-PHASE PYROLYSIS OF METAL-PHTHALOCYANINES}

\section{H.T. GYULASARYAN, G.G. AZIZBEKYAN, N.S. SISAKYAN, G.N. CHILINGARYAN, D.V. GRAPOV，Y.M. KUKUTS，E.G. SHAROYAN，A.S. MANUKYAN}

Nanocomposites of $\mathrm{Ni} @ \mathrm{C}$ in grafite-like matrix and cobalt nanoparticles in carbon nanotubes were obtained by solid-phase pyrolysis of nickel phthalocyanine $\left(\mathrm{NiC}_{32} \mathrm{H}_{16} \mathrm{~N}_{8}\right)$ and cobalt phthalocyanine $\left(\mathrm{CoC}_{32} \mathrm{H}_{16} \mathrm{~N}_{8}\right)$. The metal concentrations in the carbon matrix in both cases in $\mathrm{Ni} / \mathrm{C}$ and $\mathrm{Co} / \mathrm{C}$ are the same $-12 \mathrm{wt} \%$. The structure and morphology of the obtained samples were investigated by high-resolution scanning and transmission electron microscopy and $\mathrm{X}$-ray diffraction. The capacitive and resistive characteristics of the obtained $\mathrm{Ni} / \mathrm{C}$ and $\mathrm{Co} / \mathrm{C}$ compounds as an electrode material for supercapacitors (SC) have been investigated. The specific capacities measured by cyclic voltammetry are $12 \mathrm{~F} / \mathrm{g}$ and $8 \mathrm{~F} / \mathrm{g}$ for $\mathrm{Ni} / \mathrm{C}$ and $\mathrm{Co} / \mathrm{C}$ samples, respectively. The synthesized compounds can become a promising electrode material for supercapacitors with an electrolyte solution of $\mathrm{H}_{2} \mathrm{SO}_{4}$. 